\title{
Economic evaluation of zinc oxide nanoparticle production through green synthesis method using Cassia fistula plant extract
}

\author{
Fatmarin Zahra, Fidya Ahdiati Utami, Gabriela Chelvina Santiuly Girsang, Sri Zahra Mina Setyani Mulya, \\ Vina Dian Fentiana, Yashinta Kirana Putri, Asep Bayu Dani Nandiyanto* \\ Departemen Pendidikan Kimia, Universitas Pendidikan Indonesia, INDONESIA \\ Email": nandiyanto@upi.edu
}

\begin{abstract}
The purpose of this study was to determine the feasibility of a zinc oxide ( $\mathrm{ZnO})$ manufacturing project through a green synthesis method using plant extracts Cassia fistula and then evaluate it from an engineering and economic perspective. Several economic evaluation parameters are analyzed to inform the potential production of $\mathrm{ZnO}$ nanoparticles, such as the length of time required for an investment to return the total initial expenditure $(P B P)$, the condition of a production project in the form of a production function in years (CNPV), project benefits and so on. The results showed that the production of $\mathrm{ZnO}$ nanoparticles was very prospective. Technical analysis to produce $250 \mathrm{~kg}$ of ZnO nanoparticles per day shows the total cost of the equipment purchased to be 21,450.00 USD. PBP analysis shows that investment will be profitable after more than three years. This project can compete with PBP capital market standards because of the short investment returns. To ensure the feasibility of a project, the project is estimated from ideal conditions to the worst case in production, including labor, sales, raw materials, utilities, and external conditions.
\end{abstract}

Keywords: Zinc Oxide, Green synthesis, economic evaluation.

Received: 08/11/2020 - Accepted: 15/12/2020

\section{Introduction}

Zinc oxide $(\mathrm{ZnO})$ is an inorganic compound in the form of a white powder that is insoluble in water. This compound can be found in nature as the mineral zincite. $\mathrm{ZnO}$ crystallizes in three forms: hexagonal wurtzite, cubic zinc blende, and cubic salt rock. The wurtzite structure is the most common structure. $\mathrm{ZnO}$ can be used in various applications due to its ability to absorb ultraviolet radiation and can be a photocatalyst or photodetector because it has a wide band gap $(3.37 \mathrm{eV})$ and high bond excitation energy $(60 \mathrm{mV})$ [1]. $\mathrm{ZnO}$ exhibits interesting optical, acoustic and electrical properties and has a number of potential applications in electronics, optoelectronics and sensors. $\mathrm{ZnO}$ has great potential as a transparent electrode in photovoltaic technology, electroluminescence devices, and materials for ultraviolet emitting devices [2]. Zinc oxide $(\mathrm{ZnO})$ has various uses in various applications such as photoelectric devices, efficient absorbers, chemical and biological sensors, photocatalytic degradation [3], solar cells, sun cream raw materials which are effective in absorbing UV rays, UV lasers, light-emitting devices-diodes (LED) to photovoltaic electrodes. Recent research has shown $\mathrm{ZnO}$ has antimicrobial properties that can be used as a food packaging material. Many methods have been developed to synthesize $\mathrm{ZnO}$ nanoparticles, including direct precipitation method [4], homogeneous deposition method [5], sol-gel technique [6], hydrothermal processing method [7-8], microwave sintering method [9]. Then there are also several solid and gas based methods, such as solid-state reactions, spray pyrolysis $[10,11]$, gas phase condensation and thermal evaporation [12-14]. The synthesis of nanoparticles can also be carried out by physical or chemical means. Chemical methods such as sol-gel, precipitation and microemulsion have successfully synthesized $\mathrm{ZnO}$ nanoparticles with variations in particle shape and size. The most appropriate method for an economic evaluation analysis 
is the green synthesis method using extract Cassia fistula [15]. To confirm that $\mathrm{ZnO}$ nanoparticles were successfully produced, then the samples were characterized by using SEM and powder x-ray diffraction [16]. The choice of this method is because the green synthesis is an environmentally friendly and simple method, it does not require raw materials that are carcinogenic and expensive.

The purpose of this study was to determine the feasibility of a project for making $\mathrm{ZnO}$ nanoparticles through the green synthesis method using plant extracts Cassia fistula and then evaluating from an engineering and economic perspective. We made this paper because there is no article discusses in detail the economic evaluation of $\mathrm{ZnO}$ nanoparticle synthesis. Changing the lab scale to industrial scale on the quantity of raw materials and equipment was carried out for this study. We perform several economic variations on taxes, sales, raw materials, labor and utilities.

\section{Method}

\section{II.1. Synthesis of ZnO Nanoparticles}

Currently, green synthesis method is being developed as an alternative to make nanoparticles that are environmentally friendly and still produce nanoparticles with good characteristics. The method for obtaining $\mathrm{ZnO}$ is by burning the solution with a homogeneous mixing of combustible fuels. The mixing of zinc nitrate hexahydrate with Cassia fistula extract will produce $\mathrm{ZnO}$ nanoparticles. During the breakdown of the solution, there is an exothermic reaction between the oxidizing and reducing substance. Generally, metal nitrate derived from zinc nitrate hexahydrate acts as an oxidizing agent and fuel from cassia fistula leaf extract acts as a reducing agent. Research has stated that the method of making Cassia fistula leaf extract begins with reflux extraction [14]. However, before reflux, 0.2 grams of Cassia fistula leaves were mixed with $10 \mathrm{ml}$ of distilled water. The reflux process was carried out for 5 hours with constant stirring. The extract is filtered and centrifuged to remove insoluble material. The extract was then concentrated in an evaporator and stored at $4{ }^{\circ} \mathrm{C}$. All processes of synthesis $\mathrm{ZnO}$ nanoparticles are shown in Figure 1.

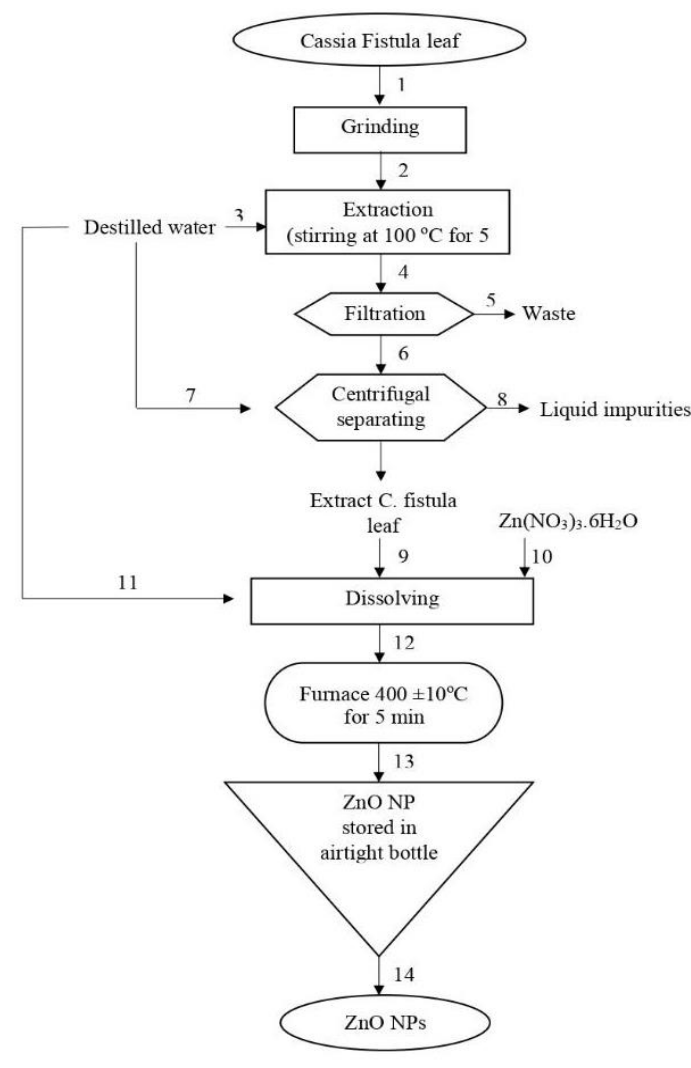

Figure 1. Synthesis of $\mathrm{ZnO}$ nanoparticles using extract Cassia fistula

\section{II.2. Economic Evaluation}

This research used a method based on the analysis of the price of materials, equipment, and equipment specifications that are commercially available on the online shopping web. All data is calculated based on simple mathematical calculations using Microsoft Excel. Economic parameter evaluation was carried out to confirm the economic evaluation of this project. Several economic evaluation parameters are used based on literature [16], economic evaluation parameters are presented in the following:

1. Gross profit margin (GPM) is the first analysis to determine the level of profitability of a project by reducing the cost of selling the product with the cost of raw materials.

2. Payback period (PBP) or fund back is a calculation done to predict the length of time it will take for an investment to return the total initial outlay. PBP is calculated when CNPV is at zero for the first time.

3. Breakeven point (BEP) is the minimum amount of product that must be sold at a certain price to cover the total cost of production. BEP can be calculated by calculating the fixed cost value divided by (total sales price less total variable cost). 
4. Cumulative net present value (CNPV) is a value that predicts the condition of a production project in the form of a production function in years. The CPNV value is obtained from the net present value (NPV) at a certain time. NPV is a value that states the expenses and income of a business. In short, CNPV is obtained by adding the NPV value from the first project to the end of the plant operation.

5. Profitability index (PI) is an index to identify the relationship between project costs and impacts. PI can be calculated by dividing the CNPV with the total investment cost (TIC). If the PI is less than one, then the project can be classified as an unprofitable project and if the PI is more than one, the project can be classified as a good project.

Some of the process-based assumptions are shown in Figure 2. These assumptions represent the stoichiometric calculations after scaling up the project which resulted in about $250 \mathrm{~kg}$ of $\mathrm{ZnO}$ nanoparticles. The assumptions are: (1) All chemical compositions in the reaction, such as zinc nitrate hexahydrate, leaf extract Cassia fistula and distilled water are used for the production of $\mathrm{MgO}$ nanoparticles. These materials are increased up to 2000 times. The ingredients are of high purity. The ingredients are counted from the literature. (2) Leaf extract Cassia fistula and zinc nitrate hexahydrate reacted in a ratio of 1 : 4. (3) The conversion rate for the zinc oxide formation process is $100 \%$.

Several assumptions are used to confirm the economic analysis. These assumptions are needed to analyze and predict some of the possibilities that occur during the project. The assumptions are:

1. All analyzes are in USD. 1 USD $=15,000$ rupiah.

2. Based on commercially available prices, the prices for zinc nitrate hexahydrate and leaf Cassia fistula are 166.67 USD / kg and 333.3 USD / kg. All materials were estimated based on stoichiometry.

3. The total investment cost (TIC) is calculated based on the Lang Factor [16,17].

4. TIC is prepared in at least two steps. The first step is $40 \%$ in the first year and the second step is the rest (during project development).

5. Land purchased. Thus, land costs are added at the beginning of the factory construction year and recovered at the end of the project.

6. Depreciation is estimated using direct calculations [16].

7. One cycle of the process for making $\mathrm{ZnO}$ nanoparticles takes 10 hours.

8. Postage costs are borne by the buyer.

9. $\mathrm{MgO}$ nanoparticles are priced at $5 \mathrm{USD} / \mathrm{pack}$.
10. One year's project is 300 days (and the rest are days spent on cleaning and organizing the process).

11. To simplify utility, utility units can be described and converted as units of electricity, such as $\mathrm{kWh}$ [18]. Then, the electricity unit is converted into cost. The unit of electricity $(\mathrm{kWh})$ is multiplied by the cost of electricity.

12. Total wages / labor are assumed to be fixed at 150 USD / day for 30 workers.

13. The discount rate is $15 \%$ per annum.

14. Income tax is $10 \%$ annually.

15. The project operation length is 20 years.

Economic evaluation is conducted for a project feasibility test. This economic evaluation is carried out by varying the value of taxes, sales, raw materials, labor and utility under several conditions. Tax variations are made at 10, 25, 50, 75 and $100 \%$. Variations in sales, raw materials, labor and utilities were carried out at 80, 90, 100, 110 and $120 \%$.

\section{Results and Discussion}

\section{III.1. Engineering perspective}

Figure 2 shows the process of making $\mathrm{ZnO}$ nanoparticles using the eco-friendly green combustion route based on literature. All the symbols in Figure 2 are informed in Table 1. From an engineering point of view, the total cost for purchasing raw materials for one year is 150,000 USD. Sales in one year were 375,000 USD. The profit earned was $100,344.39$ USD. The price for the analysis of equipment costs is 21,450 USD. The TIC must be less than 90,948.00 USD. This project requires a small investment fund. The project life span is 20 years, resulting in $\mathrm{ZnO}$ nanoparticles with CNPV / TIC reaching $2.167 \%$, in the 9 th year, and PBP has been reached in the 3 rd year.

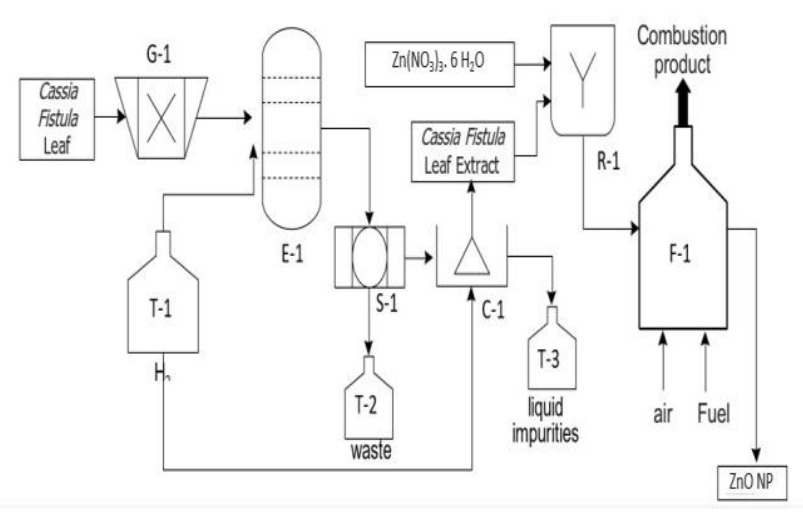

Figure 2. Process Flow diagram of $\mathrm{ZnO}$ 


\begin{tabular}{lll} 
& \multicolumn{2}{c}{ Table 1. Process Flow diagram of $\mathrm{ZnO}$} \\
\hline No & Symbol & Information \\
\hline 1. & G-1 & Grinding-1 \\
2. & T-1 & Tank-1 \\
3. & T-2 & Tank-2 \\
4. & T-3 & Tank-3 \\
5. & E-1 & Extractor-1 \\
6. & S-1 & Separator-1 \\
7. & C-1 & Centrifuge-1 \\
8. & R-1 & Reactor-1 \\
9. & F-1 & Furnace-1 \\
\hline
\end{tabular}

\section{III.2. Economic Evaluation}

\subsection{Ideal Conditions}

Figure 3 shows a graph of the relationship between the CNPV/ TIC value on the y-axis and the lifetime (year) on the $\mathrm{x}$-axis. In the curve, it can be found a negative CNVP / TIC value (\%), which is a value below 0 in the first year to the third year, which indicates a decrease in income in that year due to costs for initial capital for $\mathrm{ZnO}$ nanoparticle production. The lowest CNVP / TIC value occurred in the second year which was -0.845204551 . However, after that, the curve rises again for the first 9 years with a value reaching 1,89536589 . There is no profit from the $1^{\text {st }}$ year to the $3^{\text {rd }}$ year. This is because of the initial capital costs such as the tools needed during the process of producing $\mathrm{ZnO}$ nanoparticles. In the $3^{\text {rd }}$ year, the graph shows an increase in income, which is the Payback Period (PBP). In the $3^{\text {rd }}$ year, there is an increase until the $9^{\text {th }}$ year and the income gain is able to cover the initial capital or the capital reversal. In Table 2, the CNVP / TIC value is negative from the first to the third year. Then the CNVP/TIC value began to come back positive in the $4^{\text {th }}$ year with a value of 0.33206856 which continued to increase until the $9^{\text {th }}$ year with a value of 2.167604403 . Thus, the production $\mathrm{ZnO}$ nanoparticles can be considered a profitable project because $\mathrm{ZnO}$ nanoparticle production requires a short time to recover investment costs. This is in line with previous studies where the CNPV / TIC value decreased below 0 in the first 2 years to restore the initial total expenditure for the project. But after that, there will be an increase in the CNPV / TIC value to a positive value in economic parameters.

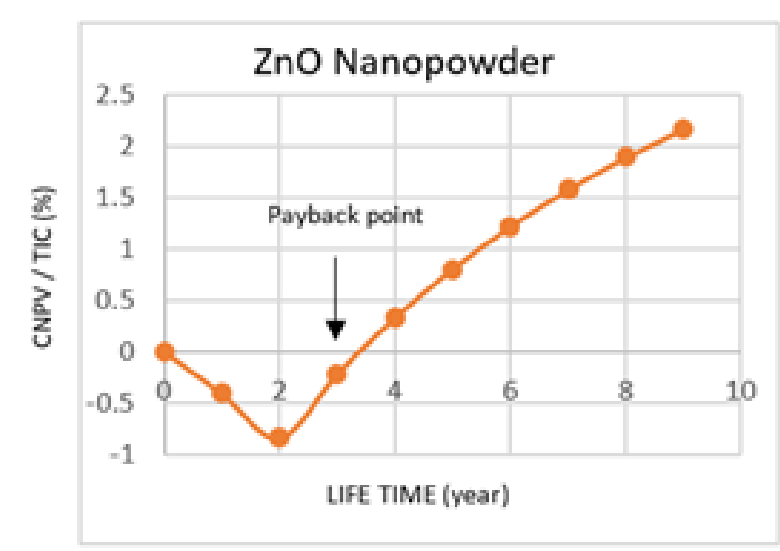

Figure 3. CNPV/TIC graph for lifetime year under ideal conditions

\begin{tabular}{ll} 
Table 2. Annual CNPV values in ideal condition \\
\cline { 2 - 2 } CNPV/TIC & Year \\
\hline 1. & 0 \\
-0.409351928 & 1 \\
-0.845204551 & 2 \\
-0.215500329 & 3 \\
0.33206856 & 4 \\
0.80821542 & 5 \\
1.222256168 & 6 \\
1.582291601 & 7 \\
1.89536589 & 8 \\
2.167604403 & 9 \\
\hline
\end{tabular}

\subsection{The Effect of External Conditions}

Economic evaluation on external factors can actually affect the success of a project. One of the factors is the tax given on projects by the country to finance various public expenditures. Figure 4 shows a graph of CNPV for 10 years with various tax variations, where the $y$-axis is CNPV / TIC and the $\mathrm{x}$-axis is a lifetime (year).

Figure 4 shows that the conditions at the beginning of the year to two years show the same results because CNPV is under tax variations and the existence of project development. In addition, in that year there was no income and there was a reduction in accordance with the ideal condition chart. An increased tax after two years can affect the CNPV value and when tax costs are added to the project it results in lower project profits. This is related to PBP because the higher the tax issued, the PBP for the initial investment capital will be longer than ideal conditions.

Funds that will return when taxes have to be paid according to the PBP analysis of $10 \%$ will be achieved in year $3 ; 25 \%$ year $3.5 ; 50 \%$ 4th year; $75 \%$ year 6 , and $100 \%$ PBP not achieved. The project profit will continue to increase when it reaches the Payback Period (PBP) point until the 10th year. CNPV / TIC values in the 10th 
year for $10,25,50,75$, and $100 \%$ were $2.17,1.69,0.89$, 0.09 and $-0.71 \%$. Therefore, the maximum tax earned for obtaining the BEP or the point where the profit or loss on the project is $75 \%$. If the tax change you get is more than $75 \%$, it can make the project fail.

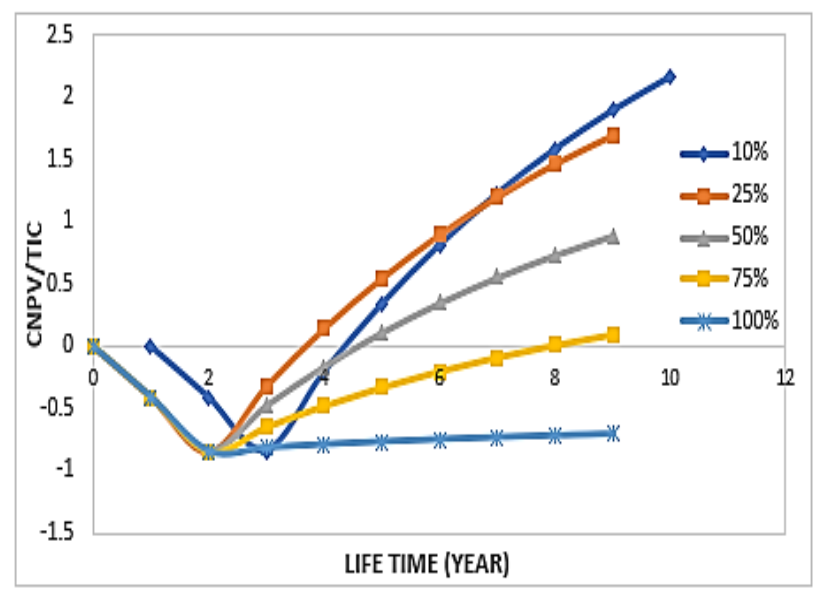

Figure 4. Graphs of CNPV for tax variations

\subsection{Change in Sales}

Figure 5 shows a CNPV chart with various sales variations. The $\mathrm{y}$-axis is CNPV / TIC and the $\mathrm{x}$-axis is the lifetime (year). The analysis was carried out by increasing and decreasing sales by $10 \%$ and $20 \%$. The ideal sales are $100 \%$ when sales are decreased by $10 \%$ and $20 \%$, the sales are $90 \%$ and $80 \%$ of the ideal $100 \%$, respectively. When sales are increased by $10 \%$ and $20 \%$, the sales will be $110 \%$ and $120 \%$.

PBP is obtained from sales variations. The results of the PBP are shown in Figure 5. The initial conditions (from 0 to 2 years of project) of CNPV under various sales variations are the same. This is due to project development. The effect of sales on CNPV can be obtained after the project is created (from 2 years). The greater the sales value, the more profits will increase from the project being undertaken. However, if there are conditions that cause product sales to decline, the project profit will decrease from the ideal state.

Based on the PBP analysis, funds returned when sales variations of $120.110,100.90$, and $80 \%$ were achieved in year 3 and PBP was not achieved. Profits continue to increase after reaching the Payback Period (PBP) point until the 9th year. PBP results for sales variations of 90, 100,110 , and $120 \%$ were achieved in year 4.5 respectively; $3.5,3$ and 2,9. $\mathrm{PBP}$ at $80 \%$ sales variation is still not achieved in the 9th year. However, the gap in profits generated for each year decreases as sales decrease and losses when sales are reduced by $20 \%$ from ideal conditions. Conversely, the profit distance generated for each year increases with increasing sales from ideal conditions. The CNPV / TIC value in the 9th year for each variation of $120,110,100,90$, and $80 \%$ is $4.50,3.33,2.16,1.00$ and $-0.16 \%$ So, the minimum sales to earn BEP (the point at which both the profit and loss on the project) is $90 \%$. Changes in sales of less than $90 \%$ result in project failures. As with $\mathrm{ZnO}$ nanoparticles sales are profitable if sales are increased by more than $100 \%$ because the graph shows a positive CNPV / TIC value, this means the project is feasible to run.

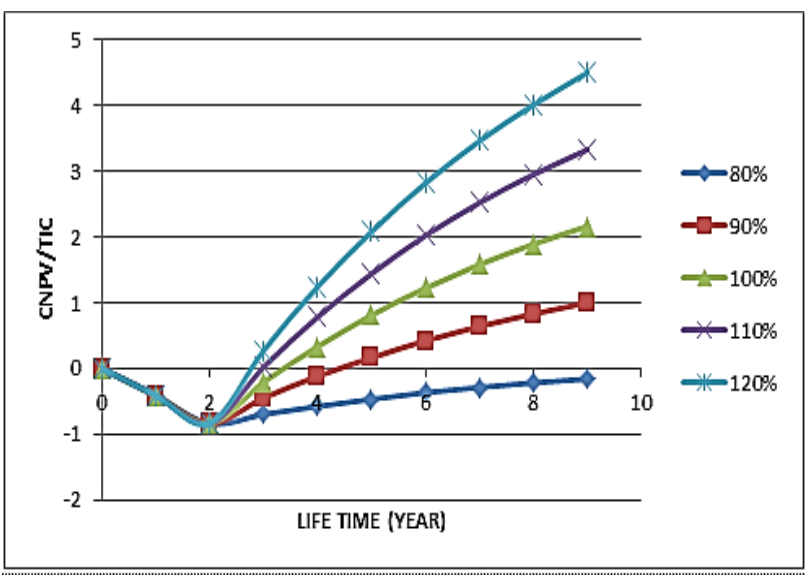

Figure 5. CNPV curve of sales variation

2.4. Change in variable cost (raw material, labor, utility)

Factors such as raw material conditions, utility, and labor can influence the success of a project. Figure 6 shows a CNPV chart with variations in raw material price. The ideal raw material price was $100 \%$. Analysis of variations in raw materials was carried out by lowering and increasing the price of raw materials by 10 and $20 \%$ from ideal conditions. The variations of the raw materials used in this analysis were 80, 90, 100, 110, and $120 \%$.

The CPNV/TIC value was constant in the initial project condition (0-2 years) because the project was still under construction. Variations in raw material price began to affect the CPNV/TIC value after 2 years of the project. The decreases in raw material expense resulted in increases in profits. However, if there is a situation that causes the price of raw materials to increase, the profits decreased.

The value of CPNV/TIC in the 9th year for the variation of raw materials $80,90,100,110$, and $120 \%$ were $3.10 ; 2.63 ; 2.16 ; 1.70$; and $1.23 \%$. PBP results from variations in raw material prices of $80,90,100,110$, and $120 \%$ were achieved respectively in the year 3.00; 3.20; $3.40 ; 3.65$; and 4.00 . The closest payback period (3 
years) with the largest profit $(\mathrm{CPNV} / \mathrm{TIC}=3.10 \%) \mathrm{can}$ be obtained from the variation of $80 \%$ raw material price.

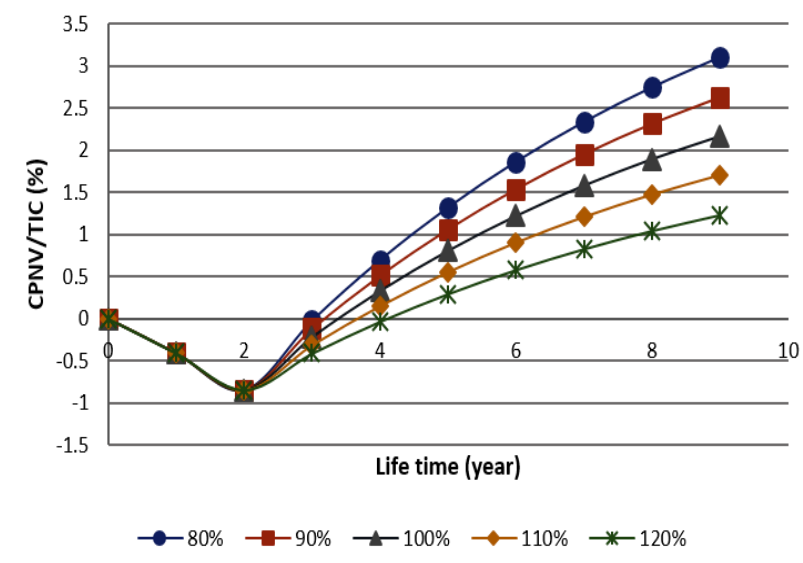

Figure 6. CPNV/TIC with raw material price variations

As shown in Figure 7, the CNPV/TIC graph is analyzed with various utility price. The analysis was carried out by decreasing and increasing utility prices by 10 and $20 \%$ from ideal conditions. The ideal utility price was $100 \%$. The utility price variations used in this analysis were $80,90,100,110$, and $120 \%$.

The CPNV/TIC value from year 0 to 2 after the project was created is constant. This was due to the project development stage. The effect of the utility price on the CPNV/TIC value can be obtained 2 years after the project is created. There was no significant effect of utility price variation on the CPNV/TIC graph. The project can still run and make a profit.

The CPNV/TIC values in the 9th year for the utility variations of $80,90,100,110$, and $120 \%$ were $2.19 ; 2.18$; $2.16 ; 2.15$; and $2.13 \%$. The PBP results from the utility variations of $80,90,100,110$, and $120 \%$ will be achieved in 3,4 since the project was created. The closest payback period (3.4 years) with the largest profit $(\mathrm{CPNV} / \mathrm{TIC}=2.19 \%)$ can be obtained from the $80 \%$ utility variation.

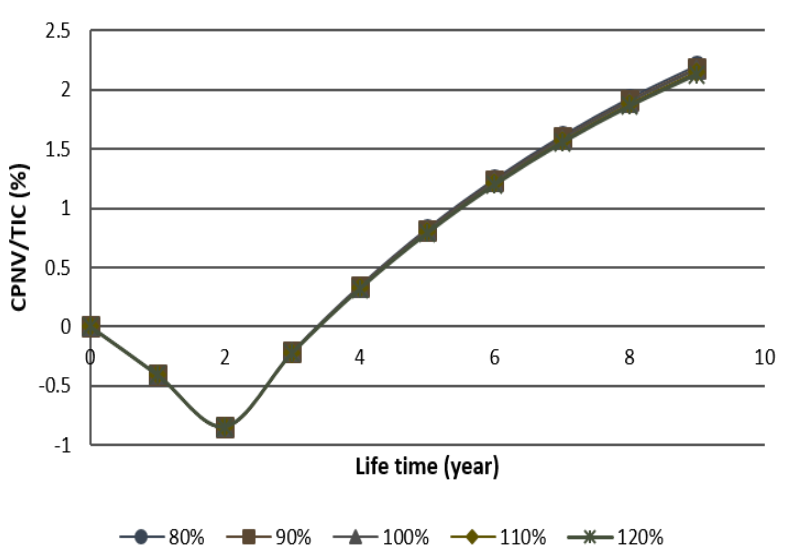

Figure 7. CPNV/TIC with utility price variations

The CNPV/TIC graph was analyzed with various labor wages as shown in Figure 8. The analysis was carried out by decreasing and increasing the wages of workers by 10 and $20 \%$ from ideal conditions. The worker's ideal salary was $100 \%$. The variations in the wages of workers used in this analysis were 80, 90, 100, 110 , and $120 \%$.

In the initial project conditions (0-2 years), the CNPV/TIC value was constant. This was obtained at the project development stage. The labor wage variations were affecting the CPNV/TIC chart after the second year since the project was created. The higher the worker's salary, the lower the project's profit. On the other hand, the biggest project profit was derived from the lower wages of the workforce. The CPNV/TIC values in the 9th year for the workers wage variations of $80,90,100$, 110 , and $120 \%$ were $2.63 ; 2.40 ; 2.17 ; 1.93$; and $1.69 \%$, respectively. The PBP results from the worker salary variations of $80,90,100,110$, and $120 \%$ were achieved in 3,$2 ; 3,3 ; 3,4 ; 3.5$; and 3.67 , respectively. The closest payback period (3.2 years) with the largest profit $(\mathrm{CPNV} / \mathrm{TIC}=2.63 \%)$ can be obtained from the worker's salary variation of $80 \%$.

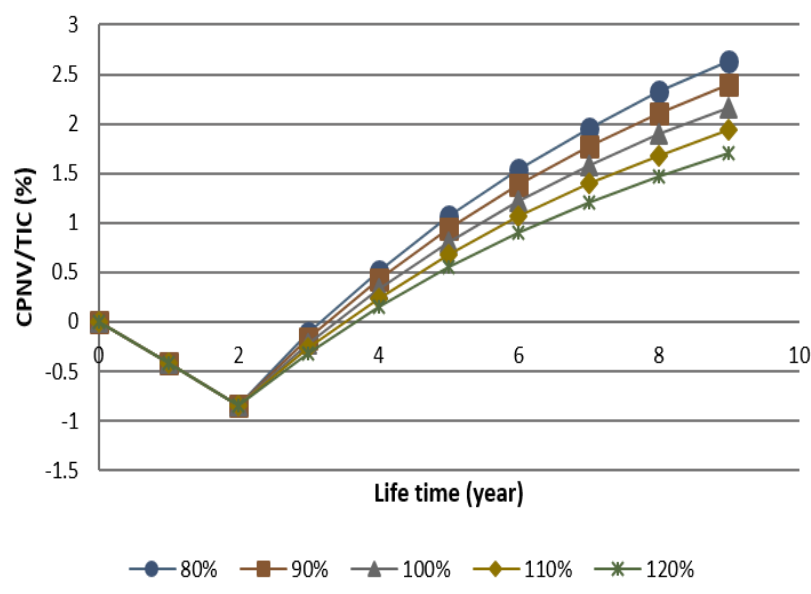

Figure 8. CPNV/TIC with worker's salary variation 


\section{Conclusion}

Based on the above analysis, the $\mathrm{ZnO}$ nanoparticle production project with green synthesis method using extract Cassia fistula is prospective from an engineering point of view and it is promising in economic evaluation. PBP analysis shows that investment is profitable after more than 3 years. This project can compete with PBP capital market standards because of the short investment returns. Some of the things that affect this benefit include using the green synthesis method, because this method is very simple, does not use hazardous materials and is cheap. From the analysis of this economic evaluation, we can conclude that this project is feasible to run.

\section{References}

[1] Z. R Dai, Z. W Pan, Z. L Wang, "Novel Nanostructures of Functional Oxides Synthesized by Thermal Evaporation", Advanced Functional Materials, Vol. 13, Issue 1, 2003, pp. 9-24

[2] M Abdullah, Khairurrijal, "Review: Karakterisasi Nanomaterial", Jurnal Nanosains \& Nanoteknologi, 2009.

[3] W. Yujum, Z. Chunling, and B. Siwei, "Preparation of ZnO Nanoparticles Using The Direct Precipitation Method In a Membrane Dispersion Micro-Structured Reactor", Powder Technology, 2010, pp.130-136.

[4] C Chen, P Liu, C Lu, "Synthesis and Characterization of Nano-sized $\mathrm{ZnO}$ Powders by Direct Precipitation Method", Chemical Engineering Journal, Vol. 144, Issue 3, 2008, pp.509-513.

[5] Y Liu, Zhou, Jian-er, A. Larbot, "Preparation and characterization of nano-zinc oxide", Journal of Materials Processing Technology, Vol. 189, 2007, pp.379-383.

[6] K. Hayat, M.A. Gondal, M.M. Khaled, "Nano ZnO synthesis by modified sol gel method and its application in heterogeneous photocatalytic removal of phenol from water", Applied Catalysis A: General, Vol. 393, 2011, pp.122-129.

[7] M H Mamat, M Z Sahdan, S Amizam, "Properties of nanostructured zinc oxide by hydro-thermal aqueous chemical growth method", AIP Conference Proceedings, 2009, pp.586-590.

[8] A. Aimable, M. T. Buscaglia, V Buscaglia, P. Bowen, "Polymer-assisted precipitation of $\mathrm{ZnO}$ nanoparticles with narrow particle size distribution", Journal of the European Ceramic Society, Vol. 30, 2010, pp.591-598.

[9] S.E Savary, Marinel, H Colder, "Microwave sintering of nano-sized $\mathrm{ZnO}$ synthesized by a liquid route", Powder Technology, Vol. 208, 2011, pp.521-525.

[10] X, Zhao, B. Zheng, C Li, and H. Gu, "Acetate-derived $\mathrm{ZnO}$ ultrafine particles synthesized by spray pyrolysis", Powder Technology, Vol. 100, 1998, pp.20-23.

[11] T Tani, L, Mädler, S. E Pratsinis, "Homogeneous ZnO nanoparticles by flame spray pyrolysis", Journal of Nanoparticle Research, Vol. 4, Issue 4, 2002, pp.337-343.
[12] J.Y. Li., X.L. Chen, H. Li, M. He, "Fabrication of zinc oxide nanorods", Vol. 233, Issue 1, 2001, pp.5-7

[13] H Kleinwechter., C. Janzen., J. Knipping, H. Wiggers, "Formation and Properties of $\mathrm{ZnO}$ nano-particles from gas phase synthesis processes", Vol. 37, 2002, pp.4349-4360.

[14] D. Suresh, P. C. Nethravathi., Udayabhanu, H. Rajanaika, H. Nagabhushana, S. C Sharma, "Green synthesis of multifunctional zinc oxide $(\mathrm{ZnO})$ nanoparticles using Cassia fistula plant extract and their photodegradative, antioxidant and antibacterial activities", Materials Science in Semiconductor Processing, Vol. 31, 2015, pp.446-454.

[15] E. R. P. Priyanda, A. Sukmafitri, A. Mudzakir, A.B.D. Nandiyanto. W. C. Nugraha, W. Ramadhani, "Zinc Oxide Nanoparticles for enhancing students view of the nature of science and technology", Indonesian Journal of Science \& Technology, Vol. 5, Issue 1, 2020.

[16] F. Nandatamadini, S. Karina, A.B.D Nandiyanto, R. Ragadhita, "Feasibility study based on economic perspective of cobalt nanoparticle synthesis with chemical reduction method" International Journal of Energetica. Vol. 4, Issue 1, 2019, pp.17-22.

[17] Bank Indonesia, "Foreign Exchange Rates". [Online]. Available: https://www.bi.go.id/en/moneter/informasikurs/referensi-jisdor/, 2020. 